\title{
BEHAVIOR OF ALUMINUM BASED COAGULANTS IN TREATMENT OF SURFACE WATER-ASSESSMENT OF CHEMICAL AND MICROBIOLOGICAL PROPERTIES OF TREATED WATER
}

DANIELA SPÎNU (GOLOGAN) - Chemist Engineer, Head of the Laboratory of Paltinu Water Treatment Plant, PhD student Technical University of Civil Engineering, e-mail: danielagologan@yahoo.com

GABRIEL RACOVITEANU - Professor, PhD, Technical University of Civil Engineering of Bucharest, Faculty of Hydrotechnics, e-mail:gabriel.racoviteanu@utcb.ro

\begin{abstract}
Pre-polymerized inorganic aluminum coagulants have high efficiency in reducing turbidity, total, dissolved, biodegradable organic carbon and microbiological content of surface waters used for drinking, while obtaining low concentrations of residual aluminum after the coagulation phase. Correlation between turbidity raw water and coagulant dose is logarithmic being influenced by temperature and organic content of surface waters.

The coagulant's effect on the organic content of the raw water is closely related to the microbiological concentration and can thus determine the mathematical correlations between the two types of parameters after the coagulation-flocculation stage that can be used to assess the water biostability coagulant action.
\end{abstract}

Keywords: pre-polymerized inorganic coagulant, poly-aluminum chloride, poly-aluminum sulfate chloride, poly-aluminum silicate chloride biodegradable organic carbon, biostability.

\section{Introduction}

Coagulation, flocculation and sedimentation are critical steps in the water treatment processes. From the historical point of view, the processes of coagulation were designed primarily for reducing turbidity, then the reduction of organic matter has become a goal of coagulation, due to the impact that organic constituents have on water biostability. Recently, attention has focused on organic matter that can be used by microorganisms as a source of nutrients, i.e. on the biodegradable component mainly composed of non-humic substances, although research in recent years has shown that 10 to $20 \%$ of the humic substances in rivers and lakes can be biodegradable $[1,2]$.

Two sets of analyzes to examine the biodegradable organic content of surface waters are widely used like:

- Biodegradable Organic Carbon (BDOC) which is the fraction (10-20\%) of dissolved organic carbon (DOC) that can be a source of nutrients for heterotrophic bacteria [3, 4];

- Assimilable Organic Carbon (AOC) is the fraction of dissolved organic carbon (1-10\%), which can be converted by a single body or a consortium of bacteria [4].

The reduction of natural organic material depends on several factors, namely: the origin and nature of the organic matter, temperature, process water treatment, such as coagulation, flocculation reagents [5].

The presence of the natural organic matter affects coagulation chemistry. Dissolved organic material is removed by the coagulants through complex reactions, followed by their removal by forming a solid or by adsorption on solid.

The coagulation process of waters containing colloidal particles and organic matter is influenced by several factors: formation of the dissolved active species after coagulant addition, the 
presence of metal precipitate, the concentration of colloidal particles and organic matter, chemical properties of these contaminants and their reactivity with dissolved species of the coagulant, coagulation $\mathrm{pH}$, coagulant structure, water alkalinity [6]. The presence of other chemical species, such as ions of calcium and ions of sulfate, influence the coagulation process in certain circumstances [7].

The research in the last ten years have shown the effect of pre-polymerized coagulants on turbidity and the organic content used for natural and synthetic raw waters [8, 9, 10, 11]. It was reported high efficiency of pre-polymerized coagulants compared to the monometal coagulants, resulting in a decrease of organic contaminants and residual concentrations of aluminum in the treated water.

World Health Organization recommends [12] the maximum permissible limit for aluminum in drinking water to be $200 \mu \mathrm{g} / \mathrm{l}$. Epidemiological studies shows a correlation between the relative concentration of residual aluminum and Alzheimer's disease incidence due to neurological effects of aluminum.

Thanks to the effects mentioned above, the coagulants with complex structures containing silicon had been tested. Recently published research [13] shows the positive role of silicon in the treatment of Alzheimer's disease.

Due to the increasing quality requirements for drinking water produced from surface water sources (before disinfection turbidity must be less than 1 NTU (Directive 98/83/EC) and less than 0,3 NTU for $95 \%$ of the samples $[14,15])$, it is necessary to increase the efficiency of coagulation-flocculation processes, in order to ensure the biostability of drinking water through advanced removal of the organic matter. In this way the risk of the by-product formation during the reaction with the disinfectants and the humic and fulvic acids is also decreased; moreover, the growth of pathogenic bacteria in distribution systems is inhibited [16, 17], growth that has an impact on humans' health.

This study presents the influence of nine aluminum coagulants on turbidity, total organic carbon, dissolved and biodegradable organic carbon. Three of the coagulants are aluminum-siliconcomponent type and the natural surface source is a second- class surface quality-(dam PaltinuPrahova); also, the present study takes into consideration the mathematical correlations established between chemical and microbiological parameters after the coagulation phase with its impact on water biostability.

The experimental research aimed to establish a correlation between the dose of coagulant and raw water characteristics: turbidity, organic matter content, temperature, which can be used on water plant technology.

\section{Material and methods}

The main objective of this study is the evaluation of aluminum sulphate and other eight different pre-polymerized coagulants efficiencies on various parameters of raw water like: turbidity, residual aluminum, total organic carbon, dissolved biodegradable permanganate index, $\mathrm{UV}_{254}$, heterotrophic bacteria, Clostridium Perfringens.

Tested coagulants are:

- SAL-aluminum sulfate $\left(17 \% \mathrm{Al}_{2} \mathrm{O}_{3}\right)$

- PAC 10UHB- polyaluminum chloride $\left[\mathrm{Al}(\mathrm{OH})_{\mathrm{a}} \mathrm{Cl}_{\mathrm{b}}\right]-10 \% \mathrm{Al}_{2} \mathrm{O}_{3} ; 12 \% \mathrm{Cl}^{-} ; 60 \%$ basicity;

- PAC 20UHB- polyaluminum chloride $\left[\mathrm{Al}(\mathrm{OH})_{\mathrm{a}} \mathrm{Cl}_{\mathrm{b}}\right]-19 \% \mathrm{Al}_{2} \mathrm{O}_{3} ; 6 \% \mathrm{CI}^{-} ; 80 \%$ basicity;

- PAC 22UHB- polyaluminum chloride $\left[\mathrm{Al}(\mathrm{OH})_{\mathrm{a}} \mathrm{Cl}_{\mathrm{b}}\right]-21,5 \% \quad \mathrm{Al}_{2} \mathrm{O}_{3} ; 9 \% \quad \mathrm{CI}^{-} ; 80 \%$ basicity;

- PAC 24UHB- polyaluminum chloride $\left[\mathrm{Al}(\mathrm{OH})_{\mathrm{a}} \mathrm{Cl}_{\mathrm{b}}\right]-23,5 \% \mathrm{Al}_{2} \mathrm{O}_{3} ; 9 \% \mathrm{CI}^{-} ; 80 \%$ basicity; 
- PAC 14HB-polyaluminum sulfate chloride $\left[\mathrm{Al}(\mathrm{OH})_{\mathrm{a}} \mathrm{Cl}_{\mathrm{b}}(\mathrm{SO} 4)_{\mathrm{c}}\right]-14 \% \mathrm{Al}_{2} \mathrm{O}_{3} ; 11 \% \mathrm{CI} ; 2 \%$ $\mathrm{SO}_{4}{ }^{2-}$; basicity $60 \%$;

- PAC UHS- polyaluminum silicate chloride $\left[\mathrm{AlSi}(\mathrm{OH})_{\mathrm{a}} \mathrm{Cl}_{\mathrm{b}}\right]-19 \% \mathrm{Al}_{2} \mathrm{O}_{3}: 80 \%$ basicity;

- PAC UHB- polyaluminum silicate chloride $\left[\mathrm{AlSi}(\mathrm{OH})_{\mathrm{a}} \mathrm{Cl}_{\mathrm{b}}\right]-22 \% \mathrm{Al}_{2} \mathrm{O}_{3} ; 80 \%$ basicity;

- PAC UHB-P-polyaluminum silicate chloride- $48 \% \mathrm{Al}_{2} \mathrm{O}_{3} ; 82 \%$ basicity.

The coagulants were tested with the jar - test method that involved: rapid mixing raw water without the addition of the reagents of $150 \mathrm{rpm} / \mathrm{min}$ for 1 minute, adding a coagulant, rapid mixing of $150 \mathrm{rpm} / \mathrm{min}$ for 3 minutes, slow mixing of $40 \mathrm{rpm} / \mathrm{min}$ for 5 minutes, 15 minutes sedimentation and then sampling supernatant.

The methods of analysis used to determine the chemical and microbiological parameters are:

- turbidity-SR EN ISO 7027/2001;

- residual aluminum-SR ISO 10566/2001;

- permanganate index - SR EN ISO 8467/2001;

- UV $\mathrm{UV}_{25}$-Standard Methods, 19th. Ed, Method 5910;

- total organic carbon (TOC),SR EN 13137/2005;

- dissolved organic carbon (DOC), 0,45 $\mu \mathrm{m}$ membrane filtration of samples and determination according to SR EN 13137/2005;

- biodegradable organic carbon (BDOC) - Method Joret - Levi inoculated in each sample of biologically active sand $[18,19]$;

- heterotrophic bacteria-SR EN ISO 6222/2004;

- Clostridium Perfringens (m-CP agar method [20].

Most of the organic substances in raw water are the humic type and the content of organic carbon is: the TOC of the raw water between 3,46 and 5,31 $\mathrm{mg} / 1 \mathrm{C}$, DOC between 2,93 and 3,5 $\mathrm{mg} / 1 \mathrm{C}$ and BDOC between 0,88 and $1,13 \mathrm{mg} / \mathrm{lC}$. The content of the heterotrophic bacteria in the raw water are 65 to $150 \mathrm{CFU} / \mathrm{ml}$, Clostridium Perfringens between 10 and 72/100 $\mathrm{ml}$ and organic substance calculated as permanganate index between 1,18 and 7,92 $\mathrm{mg} / 1 \mathrm{O}_{2}$.

\section{Results and discussion}

\subsection{Coagulants action on raw water turbidity}

The raw water turbidity during the experiments was in the range of 3 and 1000 NTU, and the water $\mathrm{pH}$ varied between 8,0 and $8,3 \mathrm{pH}$ units.

To assess the performance of each coagulant, effectiveness in reducing turbidity has been calculated for each level of turbidity and coagulant-equation (1) followed by averaging the efficiencies obtained for the range of 3-1000 NTU turbidity-equations (2).

Where:

$$
\operatorname{EFRT}(k)=\frac{T \text { raw water }-T(i s)}{\text { Traw water }}
$$

EFRT - efficiency of turbidity reduction ;

$\mathrm{k}=$ turbidity level of raw water;

$\mathrm{T}=$ turbidity of raw water $-\mathrm{NTU}$;

is $=$ supernatant of coagulant $\mathrm{i}, \mathrm{i}=1,9$;

$$
E F R T m=\frac{\sum_{k=1}^{n} E F R(k)}{n}
$$


Where:

EFRm $=$ average efficiency of turbidity reduction - range 3-1000 NTU;

$\mathrm{k}=$ turbidity of raw water;

$\mathrm{n}=$ total levels of turbidity number at which the experiments were concludent.

The results are shown in Figure 1.

Poly-aluminum sulfate chloride (PAC 14HB) and the poly-aluminum silicate chloride (PAC UHS, PAC UHB-P) type reagents had the best behavior turbidity removal. Pre-hydrolyzed coagulants are at least $20 \%$ more efficient for turbidity decrease of raw water than aluminum sulfate.

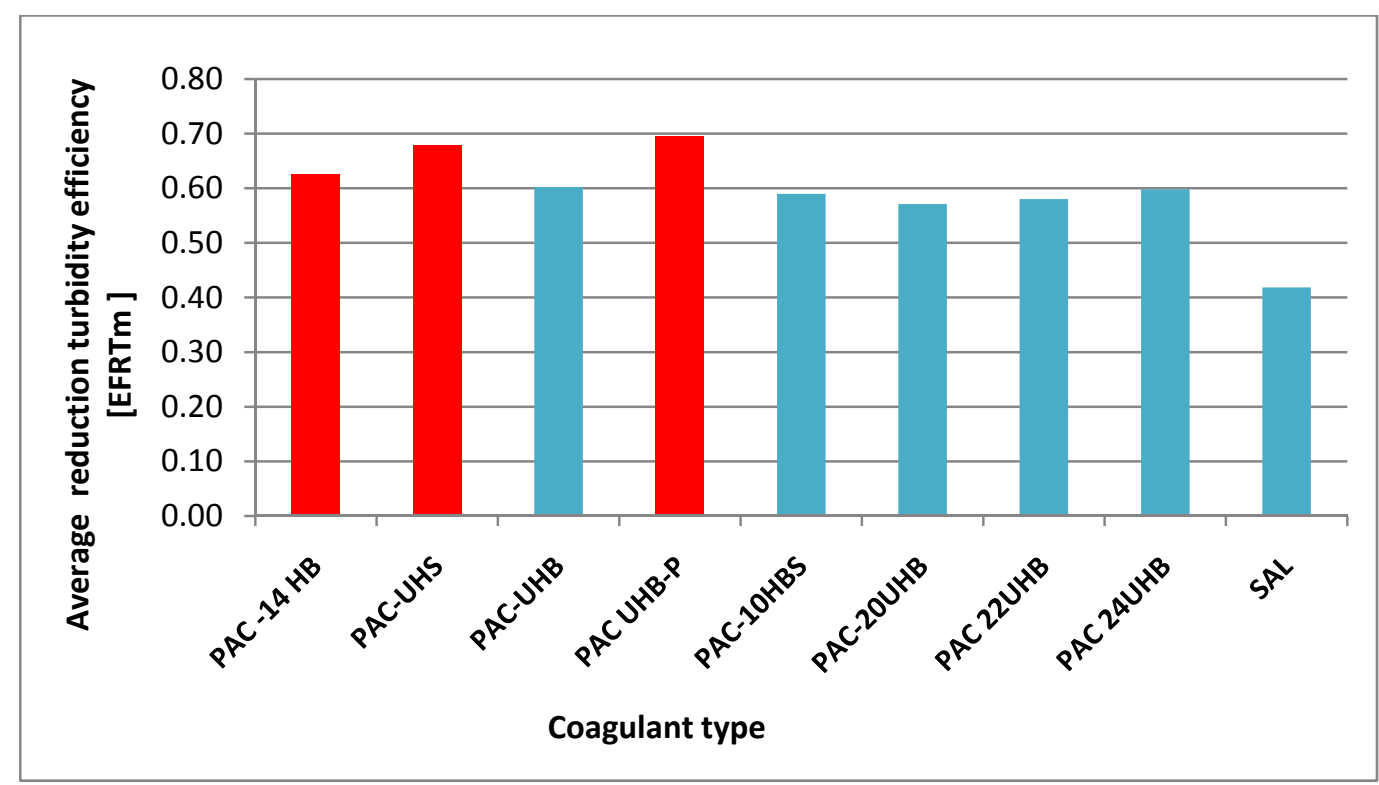

Fig. 1 - Average efficiency of turbidity removal for different coagulants. Raw water turbidity between 3 and 1000 NTU.

The tests revealed the increased bi-component coagulant action (sulfate-chloride and aluminum-silicate PAC 14HB and PAC UHS, PAC UHB-P) on low turbidity of raw water at cold temperature- Figure 2.

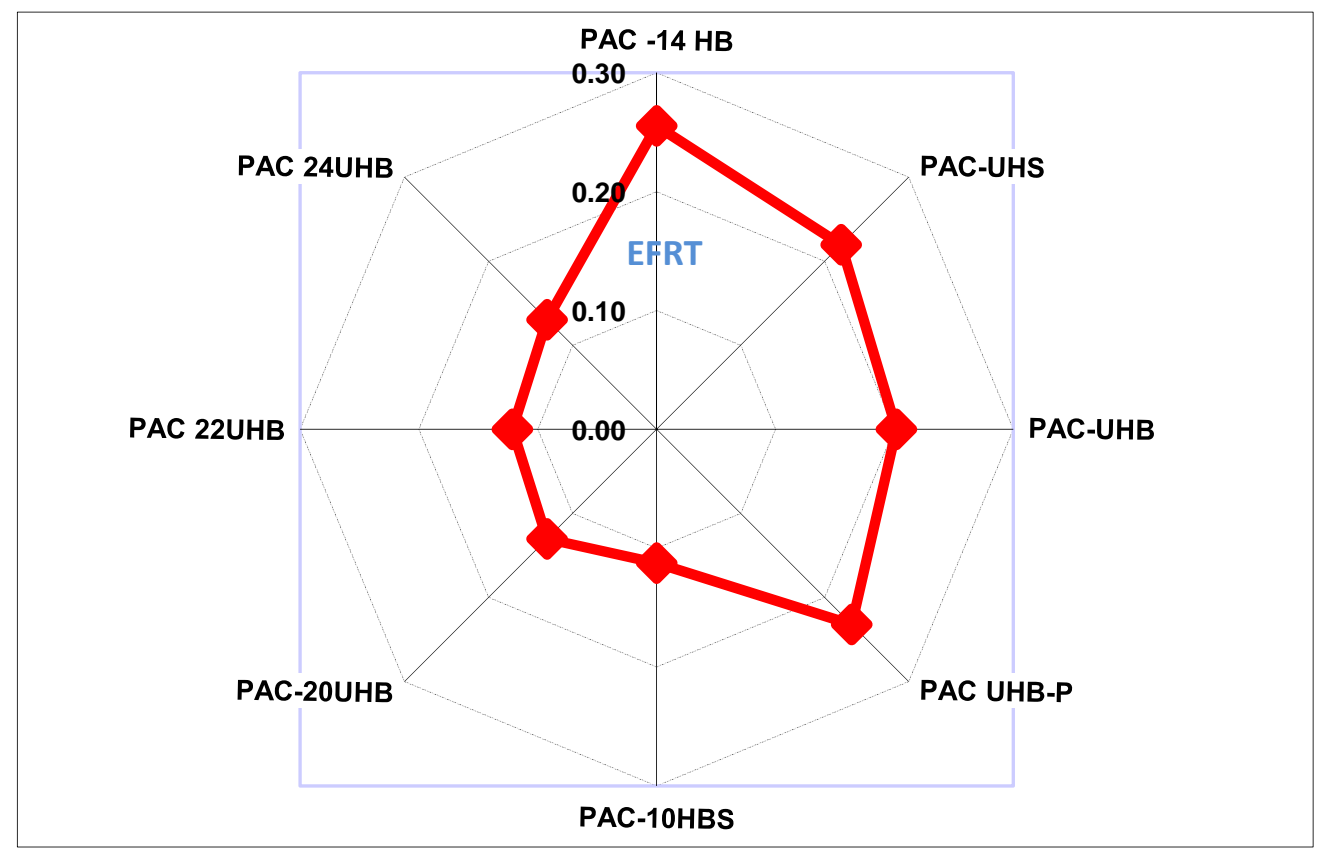

Fig. 2 -The efficiency of pre-hydrolyzed coagulants of raw water low turbidity Raw water: turbidity $=5 \mathrm{NTU}, \mathrm{pH}=8,23$, temperature $=2,60 \mathrm{C}$. 


\subsection{Residual aluminum concentration after coagulation phase}

Figure 3 shows the medium concentrations of residual aluminum in the range of 3-1000 NTU raw water turbidity for each tested coagulant.

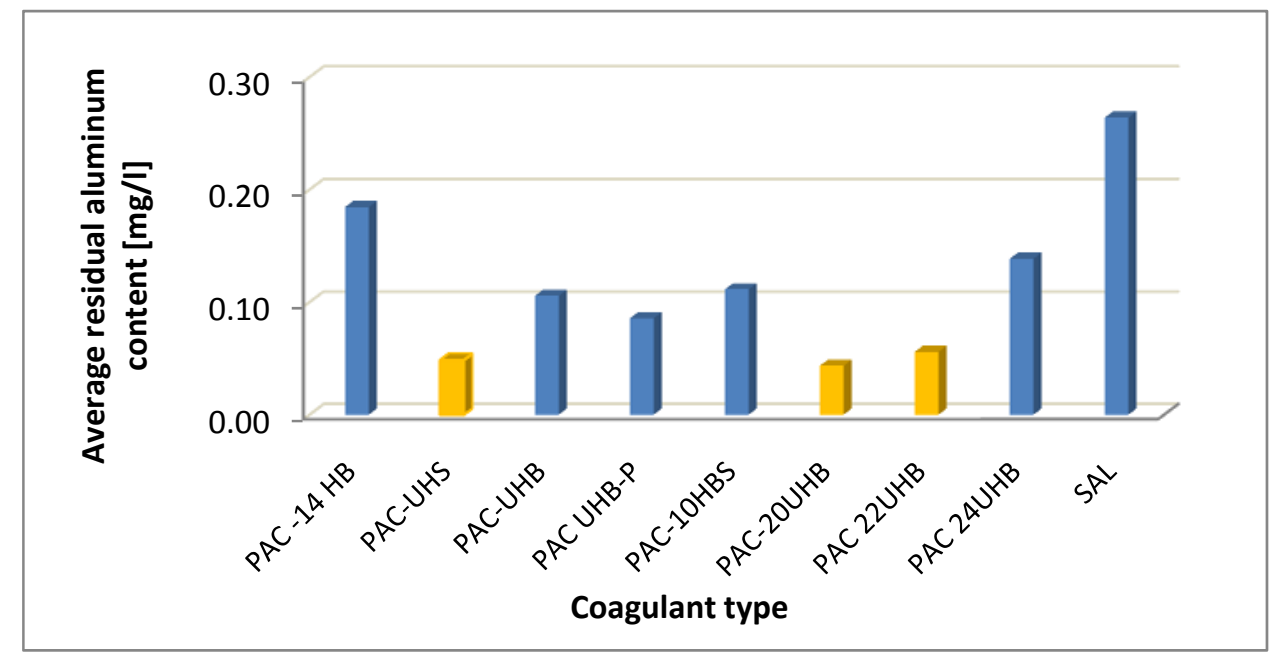

Fig. 3 - Medium concentration of residual aluminum 3-1000 NTU raw water turbidity range for tested coagulants.

The test results for the residual aluminum concentration in supernatant, shows that the polyaluminum chloride coagulant type: PAC 20,PAC 22UHB and the poly-aluminum silicate chloride PAC UHS presents the best results. These coagulants type content of $19-22 \% \mathrm{Al}_{2} \mathrm{O}_{3}$ and have $80 \%$ basicity which determine a good performances in raw water turbidity removal and low residual aluminum concentration in clarified water.

\subsection{Mathematical correlation between raw water turbidity-and coagulant dose}

In order to determine the mathematical relationship between the dose of the coagulant and the turbidity of raw water a mathematical regression of the optimal dosage coagulant in the range of 8-1000 NTU of raw water was performed.

For aluminum sulfate, the mathematical relationship between the turbidity of raw water and the dose of coagulant is shown in Figure 4.

The use of aluminum sulfate is recommended for raw water turbidities above 20 NTU. Below this value, the efficiency is lower and the residual aluminum concentration exceeds the limit allowed in legal regulation.

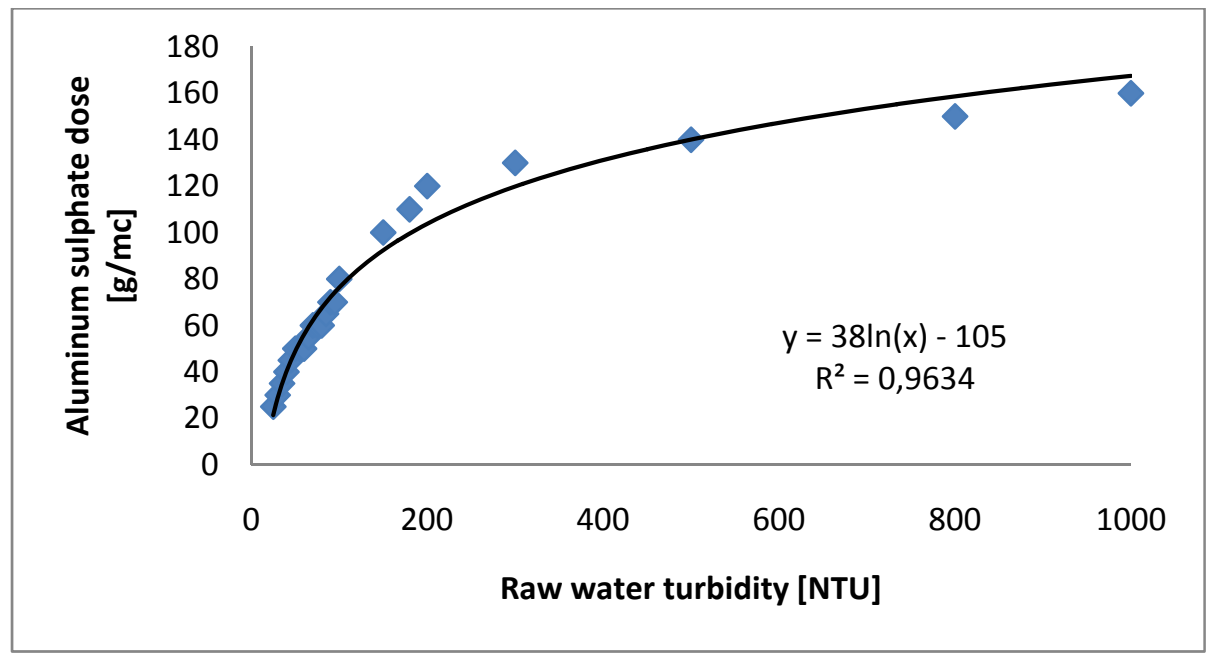

Fig. 4 - Mathematical correlation: raw water turbidity-aluminum sulfate dose 
To quantify the influences of temperature, organic substance concentration and flocculant, comparisons and mathematical regressions with the collected data from the water treatment plant monitoring were performed in a period of four years and the obtained results are presented in relation (3).

Where:

$$
S A L \text { dose }=a t * b f[38 \ln (T b)-105]+3,8 I P
$$

SAL dose - aluminum sulfate dose $(\mathrm{g} / \mathrm{mc})$

at - raw water temperature coefficient

at $=1,3-0,02 \mathrm{t}$

$t$ - raw water temperature, (0C)

$b f$ - coefficient which takes into account the addition of flocculant and between 1 and 1,2 depending on the nature and amount of flocculant added.

bf -1.2 when no flocculant is added

$\mathrm{Tb}$ - raw water turbidity (NTU)

$I P$ - raw water organic content expressed as permanganate index, in $\mathrm{mg} / \mathrm{l} \mathrm{O} 2$, according to SR ISO $8467 / 2001$

From pre-polymerized aluminum coagulants, dose and turbidity raw water mathematical relationship is presented in figure 5 .

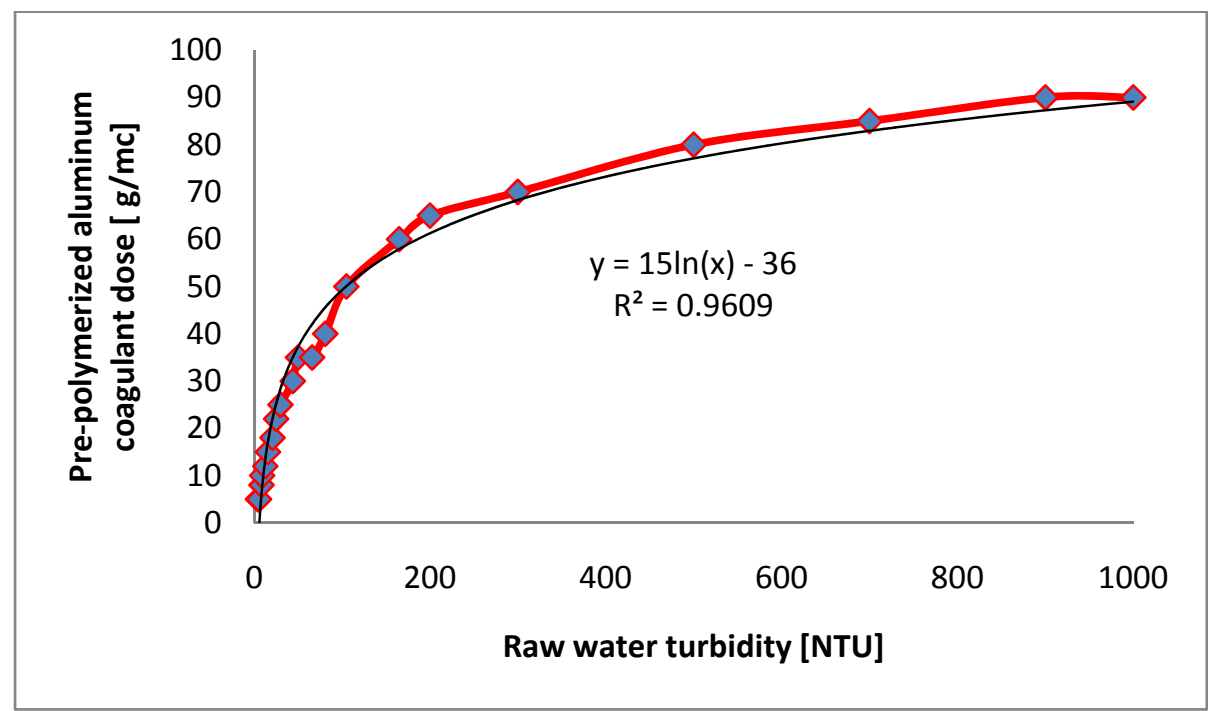

Fig. 5 - Correlation raw water turbidity, coagulant dose from pre-polymerized aluminum coagulants.

The correlation between the raw water turbidity and the coagulant dose is the logarithmic type and is applicable for raw water turbidity above 10 NTU. The regression coefficient is $\sim 0.96$.

The influence of temperature and the concentration of organic matter were determined by assessing the comparative data from the process for a two-year period and the following relation (5). was obtained

$$
\text { Dose } C P R=a t * b f[15 \ln (T b)-36]+2,28 I P
$$

Where:

$C P R=$ pre-hydrolyzed aluminum coagulant dose $\left(\mathrm{g} / \mathrm{m}^{3}\right) ;$

$\mathrm{Tb}=$ raw water turbidity (NTU); $\mathrm{Tb}>10 \mathrm{NTU}$;

$b f$ - coefficient which takes into account the addition of flocculant and between 1 and 1,2 ,depending on the nature and amount of flocculant added; 
$b f=1,2$ when no flocculant is added;

$I P=$ raw water organic content expressed as permanganate index, in $\mathrm{mg} / 1 \mathrm{O}_{2}$, according to SR ISO $8467 / 2001$;

$a t=$ coefficient that takes in to account the raw water temperature at=1,2-0,01t;

$t=$ raw water temperature $\left({ }^{0} \mathrm{C}\right)$.

\subsection{Coagulant action on raw water organic carbon content}

Each coagulant action was evaluated concerning total organic carbon (TOC), dissolved organic carbon (DOC), biodegradable organic carbon (BDOC) in the raw water, by calculating the reduction degree determined by them, for each carbon form $(6,7,8)$.

$$
\begin{aligned}
& \text { Degree of reduction of TOC }=\text { TOC raw water }- \text { TOC }(\text { is }) \\
& \text { Degree of reduction of DOC }=\text { DOC raw water }- \text { DOC (is) } \\
& \text { Degree of reduction of BDOC }=\text { BDOC raw water }-B D O C(\text { is })
\end{aligned}
$$

is $=$ supernatant of coagulant $\mathrm{i}, \mathrm{i}=1,9$

summary of the results is shown in Figure 6, which shows the effect of each test coagulant of raw water organic carbon forms.

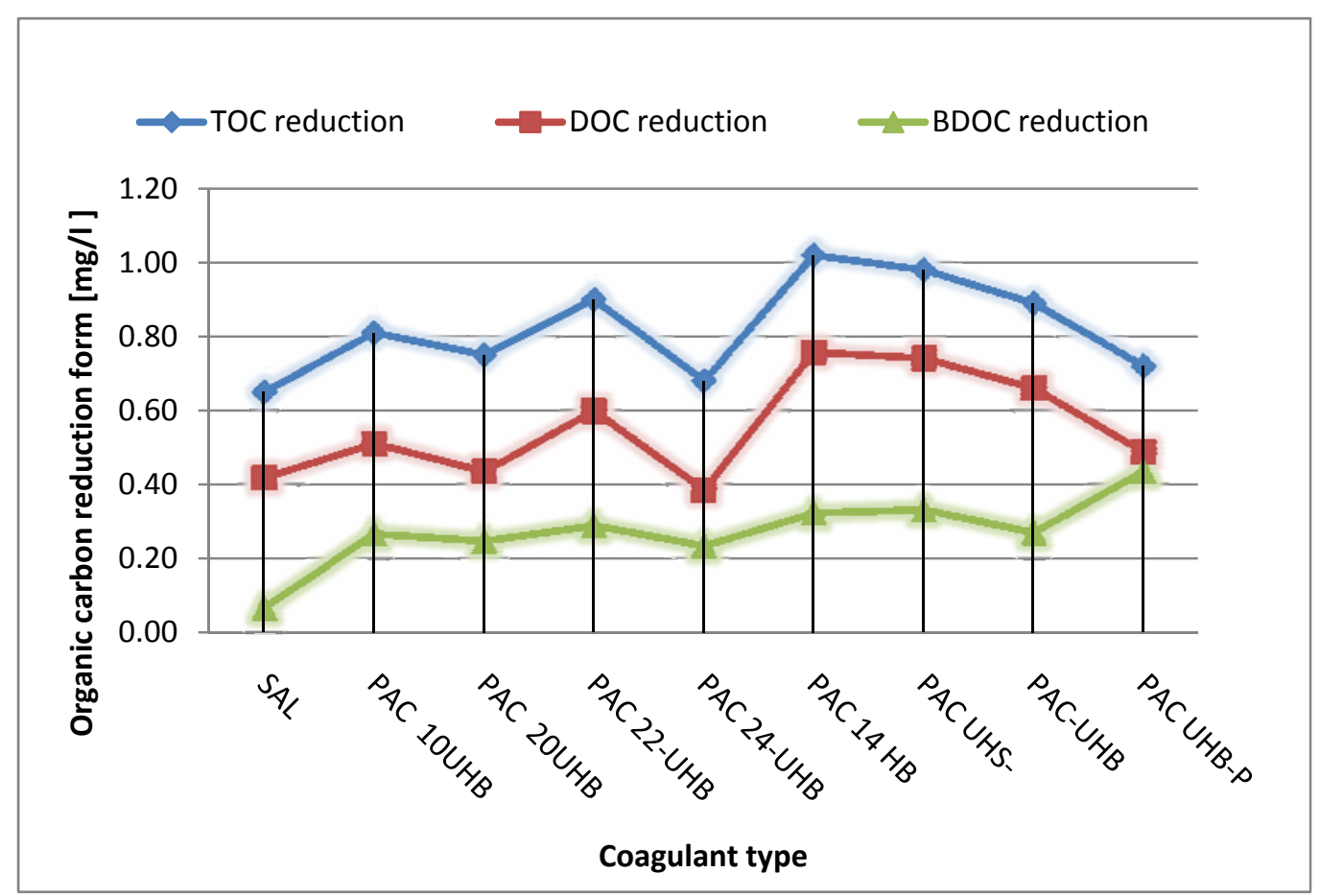

Fig. 6 - The effect of coagulant of raw water organic carbon: TOC (total organic carbon), DOC (dissolved organic carbon), BDOC (biodegradable organic carbon).

Poly-aluminum sulfate chloride (PAC $14 \mathrm{HB}$ ) and poly-aluminum silicate chloride (PAC UHS) had the best behavior on TOC and DOC reduction. PAC 22 UHB poly-hidroxichloridescoagulant types have also good results.

In reducing BDOC, the solid poly-aluminum silicate chloride (PAC UHB-P) presents the best behavior followed by the anion or cation bi-component poly-aluminum coagulant type (PAC UHS and PAC 14HB). Aluminum sulfate has the lowest degree on biodegradable carbon reduction. 


\subsection{Mathematical correlations on chemical and microbiological indicator determination after coagulation phase}

To determine a mathematical correlation between chemical and microbiological indicators of the supernatant, the chemical indicators were analyzed, after each series of jar test.

\subsubsection{Mathematical correlation between DOC-BDOC after coagulation phase}

The first correlation was established between the organic biodegradable carbon content and the logarithmic concentration of the dissolved organic carbon in the supernatant - Figure 7.

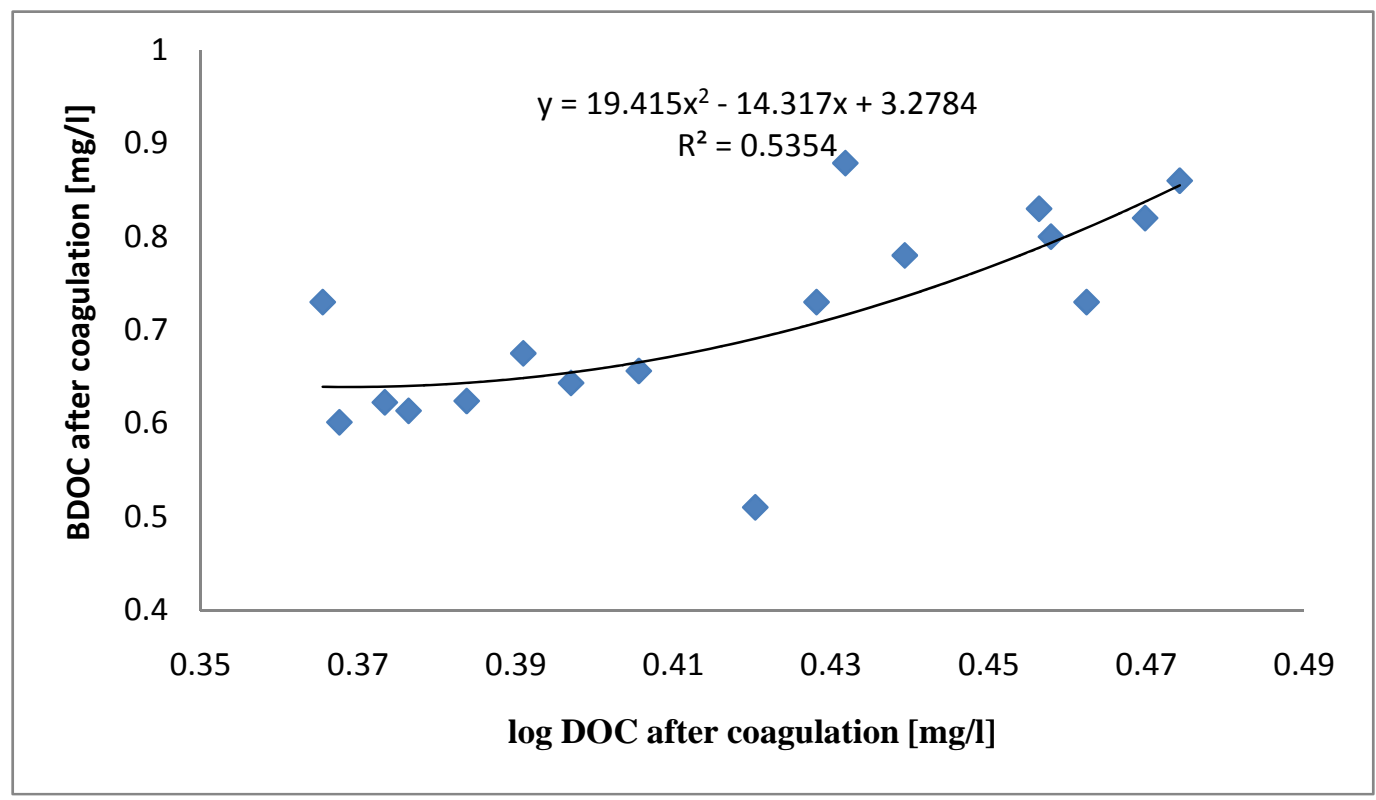

Fig. 7 - Mathematical correlation between the carbon content and the logarithm concentration of biodegradable dissolved organic carbon after the coagulation phase.

The dependence between the two results is a degree two polynomial one and points out the fact that the effect of the coagulants is both on reducing dissolved organic matter and on the biodegradable one. The impact of dissolved organic carbon is at least ten times higher than biodegradable dissolved organic carbon.

This correlation can assess the effect that one coagulant may have on organic biodegradable carbon knowing the amount of dissolved organic carbon. Thus, the analysis time can be reduced from five days to several hours.

\subsubsection{Mathematical correlation between reducing heterotrophic bacteria efficiency reduction degree of BDOC after coagulation phase}

The reduction efficiency of the heterotrophic bacteria was calculated as:

Where:

$$
E F R \log (B H T)=\frac{\log (B H T) \text { raw water })-\log (B H T) \text { is }}{\log (B H T) \text { raw water }}
$$

EFR $\log (\mathrm{BHT})=\log$ arithmic reduction efficiency of heterotrophic bacteria

$\mathrm{BHT}=$ heterotrophic bacteria $-\mathrm{CFU} / \mathrm{ml}$

is $=$ supernatant of coagulant $\mathrm{i}, \mathrm{i}=1,9$

To determine a correlation between logarithmic reduction efficiency of heterotrophic bacteria and degree of reduction BDOC calculated according to equation (8), math regression was performed -figure 8 


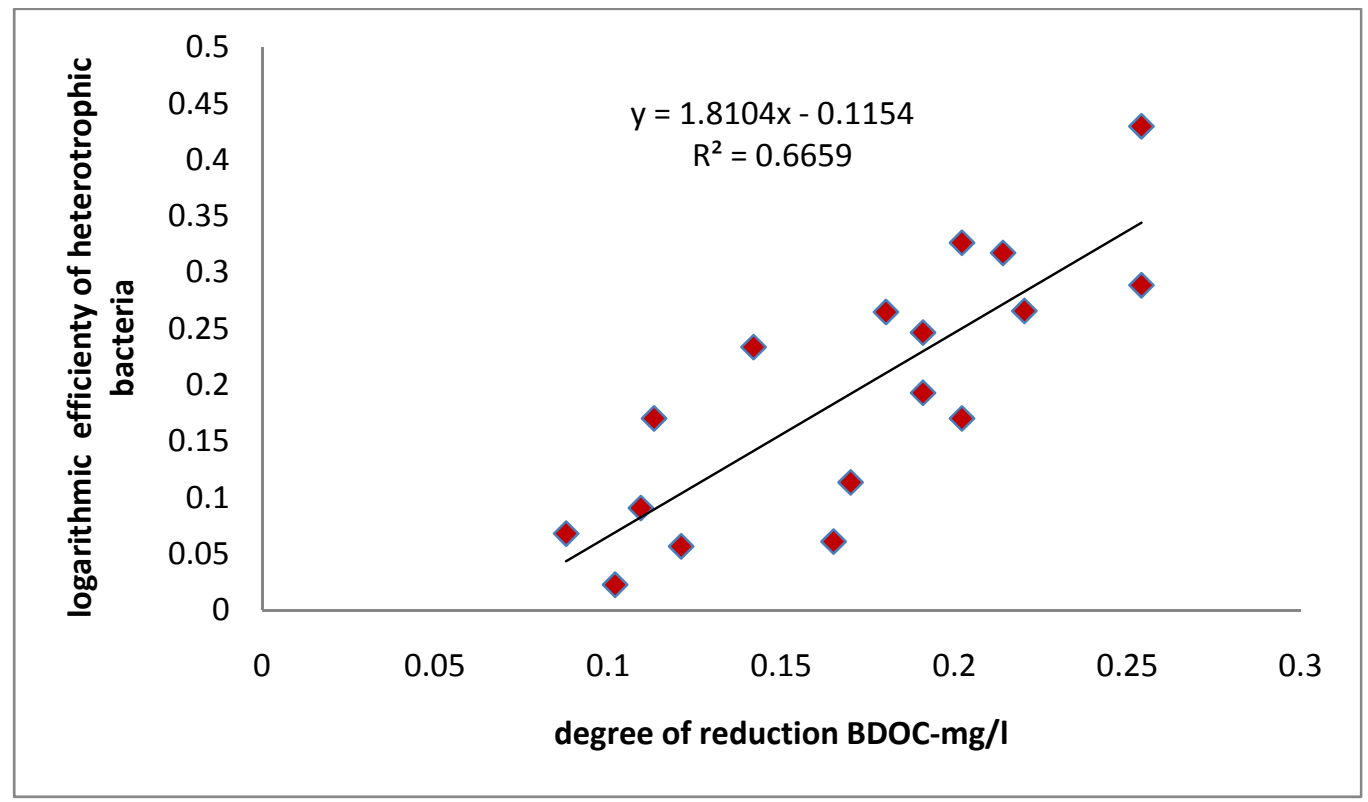

Fig. 8 - Mathematical correlation between the logarithmic efficiency of heterotrophic bacteria reduction degree of reduction BDOC after coagulation.

The linear correlation between the logarithmic reduction degree of heterotrophic bacteria and the reduction degree of biodegradable carbon is useful in water treatment for evaluating the efficiency of the coagulation process because the analyzes for the determination of heterotrophic bacteria are more affordable.

\subsubsection{Mathematical correlation turbidity reducing efficiency of Clostridium Perfringens after the coagulation phase}

Clostridium Perfringens is a gram - positive, anaerobic sulfite-reducing that produces spores resistant to unfavorable conditions in the aquatic environment such as UV radiation, high temperature, acid or alkaline $\mathrm{pH}$, and disinfection processes is a highly specific indicator of fecal pollution.

Due to the exceptional resistance of Clostridium Perfringens spores to disinfection processes and other unfavorable environmental conditions, this bacterium has been proposed as an indicator of enteric viruses and protozoa in drinking water by the World Health Organization.

In order to determine a correlation with turbidity after the coagulation phase the reduction efficiency relation was introduced according to turbidity (10).

Where:

$$
\operatorname{EFR} \log (T)=\frac{\log (T) \text { raw water }-\log (T) \text { is }}{\log \text { Traw water }}
$$

EFRlog $(\mathrm{T})=\log$ arithmic turbidity reducing efficiency

T=turbidity- NTU

is=supernatant of coagulant $i, i=1,9$

and Clostridium Perfringens reducing efficiency calculated according to equation:

Where:

$$
\text { EFRlog }(C P)=\frac{\log (C P) \text { bruta }-\log (C P) i}{\log (C P) \text { bruta }}
$$

EFRlog $(\mathrm{CP})=\log$ arithmic Clostridium Perfringens reducing efficiency

$\mathrm{CP}=\mathrm{Clostridium}$ Perfringens- units $/ 100 \mathrm{ml}$ supernatant of coagulant $\mathrm{i}, \mathrm{i}=1,9$ 


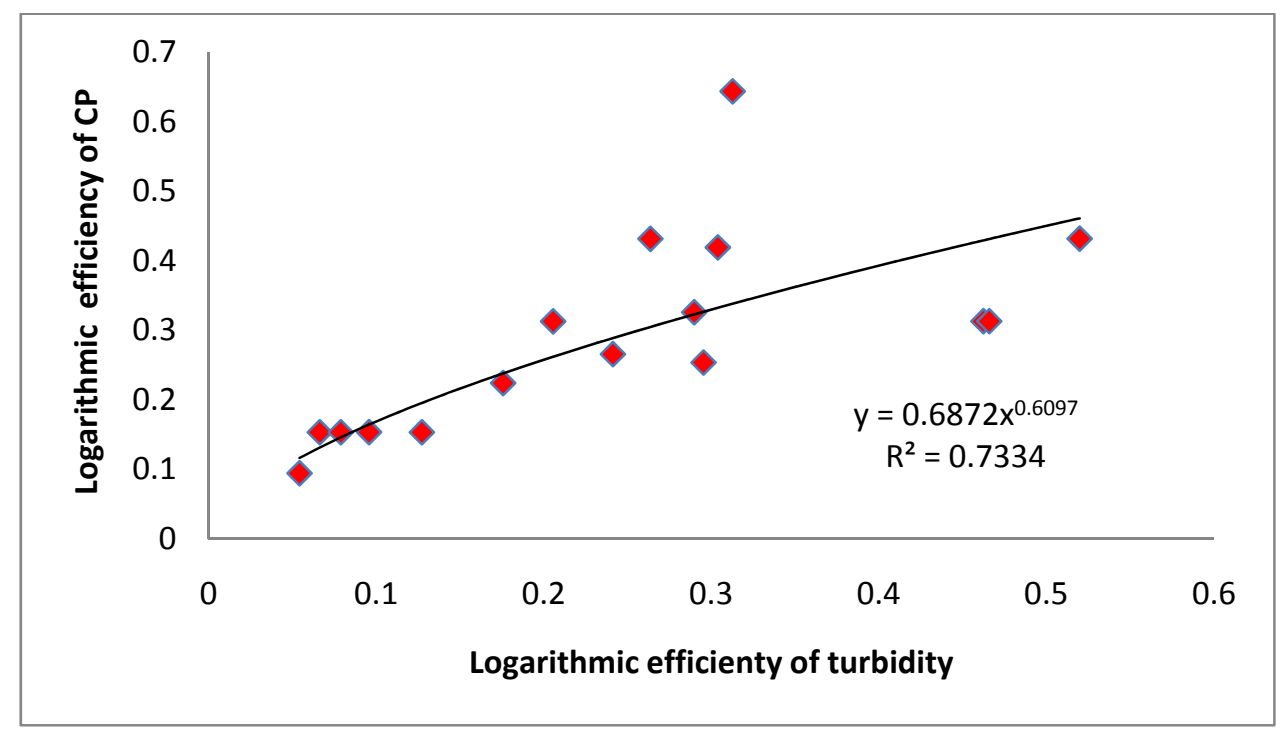

Fig. 9 - Mathematical correlation between turbidity reducing efficiency and Clostridium Perfringens reduction efficiency.

This correlation underlines that achieving an as low as possible turbidity after the coagulation flocculation stage - implies also a low pathogen concentration and this can be used at technological level, because the turbidity determinations are fast and there is a wide range of turbidity devices that can measure this parameter on line.

3.5.4 Mathematical correlation between turbidity reducing efficiency and SUVA index In order to determine the correlation between turbidity and SUVA index after the coagulation phase the logarithmic turbidity reducing efficiency was calculated by equation(10) and SUVA index by equation (12).

Where:

$$
S U V A=\frac{U V 254}{D O C} * 100
$$

SUVA - specific ultraviolet absorbance index

DOC - dissolved organic carbon - $\mathrm{mg} / \mathrm{l} \mathrm{C}$

$\mathrm{UV}_{254}$ - specific absorbance at $254 \mathrm{~nm}$ according to-Standard Methods, 19th. Ed, Method 5910

Determined correlation is shown in figure 10.

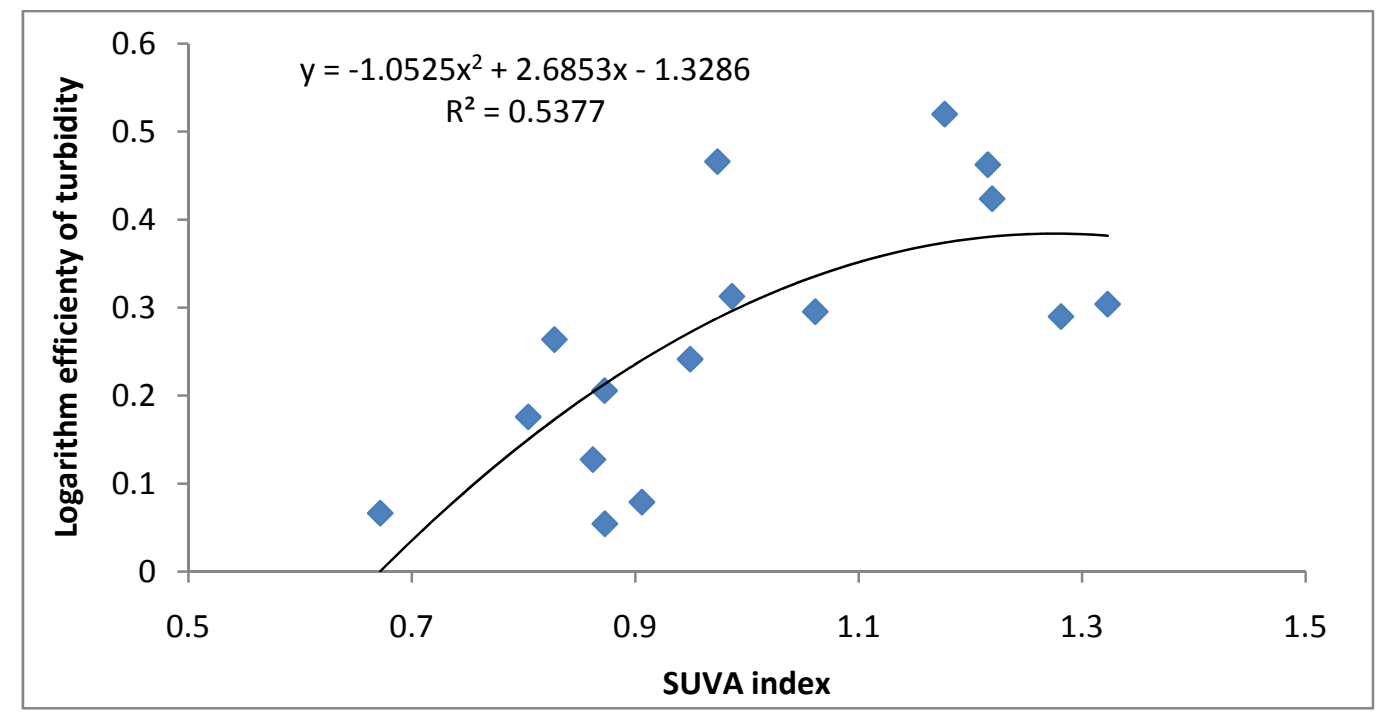

Fig. 10 - Mathematical correlation between the turbidity reducing efficiency and SUVA index. 
Although the degree of correlation is low $\mathrm{R}^{2}=0.54$, one can conclude that a high suspension reducing efficiency in water increases the SUVA index to values above 1.

\section{Conclusions}

The chemical structure and the composition of the coagulant have an important role on the decrease degree of organic and microbiological content on raw water.

Pre-polymerized inorganic aluminum coagulants are more efficient in the reduction of organic carbon even at low raw water temperatures and $\mathrm{pH}$ range from 8 to 8,3 .

The two-component type poly-aluminum chloride coagulants have greater reducing organic carbon efficiency than mono-component type coagulants due to the enlargement active species, due to both the bi-component of the cationic components. Poly-aluminum silicate chloride and the aluminum-component anionic poly-aluminum sulfate chloride present significant results for all tests carried out.

Bi-component aluminum silicate coagulant is an option for the optimization of the coagulationflocculation for the increase of turbidity reducing efficiency combined with low concentrations of residual aluminum coagulants.

Thanks to the flocculation determined by silicate compounds, the coagulant may be used without the addition of a flocculants with decrease operating costs.

The determination of some mathematical relationships between the raw water turbidity and the coagulant dose with a regression coefficient greater than 0,96 provides a high degree of certainty to the mathematical formulas that can be used on the treatment plant.

The correlations due to the coagulant dose was tested in situ over a period of two years, and therefore it may be useful in treatment plants in the sizing of the coagulation - flocculation as well for reducing the time of dose adjustment of the coagulation reagent for changing of surface water quality.

Mathematical correlations between chemical and microbiological indicators after coagulation-flocculation stage provide a basis for evaluating the coagulation treatment efficiency by analyzing indicators that take time and scarce resources (turbidity,UV 254, heterotrophic bacteria). For that a logarithmic efficiency indicator was introduced that allowed to correlate chemical and microbiological parameters after the coagulation stage.

\section{References}

[1]. C. Volk, C. Renner, C. Robert, J. C. Joret. (1994).Comparison of two techniques for measuring biodegradable dissolved organic carbon in water, Environ. Technol. 15, (pp.545-556).

[2]. C. Volk, L Kaplan, M LeChevalier. (2005)-Fluctuations of Dissolved Organic Matter in River Used for DrinkingEnviron. Sci. Technol. 39, (pp. 4258-4264).

[3]. Van der Kooij D.(1987). The effect of treatment on assimilable organic carbon in drinking water.(ed. P. M. Huck and P. Toft), (pp. 317-328), Pergamon Press, New York,

[4]. Van der Kooij, D. (1992) Assimilable organic carbon as an indicator of bacterial regrowth. J. Am. Water Works Assoc. 84, (pp. 57-65).

[5]. EPA - Office of Water (4601M) Effect of Treatment on Nutrient Availability U.S. Environmental Protection Agency Office of Ground Water and Drinking Water Standards and Risk Management No. 2 Division 1200 Pennsylvania Ave., NW Washington DC

[6]. Letterman, R. D., R. Chappell, \& B. Mates. (1996). Effect of pH and alkalinity on the removal of NOM with Al and Fe salt coagulants. In Proceedings of the AWWA Water Quality Technology Conference, November 1721, Boston, MA.

[7]. Eikebrokk, T. Juhna and S. W. Østerhus. (2006). Water treatment by enhanced coagulation - Operational status and optimization issues -Techneau D 5.3.1-December

[8]. B. Y Gao\&Yue (2005). Effect of $\mathrm{SO}_{4}^{2-} / \mathrm{Al}^{3+}$ ratio and $\mathrm{OH} / \mathrm{Al}^{3+}$ value on the characterization of coagulant poly-aluminum-chloride-sulfate (PACS) and its coagulation performance in water treatment Chemosphere,61(4), (pp.579-584).

[9]. B. Y Gao. (2007) Coagulation performance of polyaluminum silicate chloride(PASiC) for water and wastewater treatment separation and purification technolog. 56, (pp.225-230). 
[10]. B. Y. Gao, Q. Y. Yue, B. J. Wang, Y. B. Chu. (2003).Poly-aluminum-silicate-chloride (PASiC) - a new type of composite inorganic polymer coagulant, Colloids Surf. A: Physicochem. Eng. Aspects 229 (1-3) (pp.121127).

[11]. J. P. Boisvert, C. Jolicoeur. (1999). Influences of sulfate and/or silicate present in partially prehydrolyzed Al(III) flocculants on Al(III) speciation in diluted solutions, Colloids Surf. A: Physicochem. Eng. Aspects 155(2), (pp.161-170).

[12]. Guidelines for Drinking-water Quality-OMS-2011

[13]. C. Exley. (2012) - A Silicon - Rich Mineral Water Therapy for Alzheimer's Disease. Journal of Alzheimer's Disease Volume 33.

[14]. National Primary Drinking Water RegulationsEPA-USA-2009

[15]. National Secondary Drinking Water Regulation- EPA-USA-2009

[16]. Geldreich.(1996). E. E. Microbial Quality of Water Supply in Distribution Systems. Lewis Publishers

[17]. LeChevallier, M. W., W. Schulz, and R. G. Lee. (1991). Bacterial nutrients in drinking water. Applied and Environmental Microbiology, 57(3). (pp.857-862).

[18]. J. C. Joret, Y. Levi, C. Volk. (1991).Biodegradable dissolved organic carbon (BDOC) content of drinking water and potential regrowth of bacteria, Water Sci. Technol. 2. (pp. 95-101).

[19]. Racoviteanu G. (1998).Optimization of technological schemes of drinking water plant,PhD thesis, Faculty of Civil Engineering-UTCB Bucharest

[20]. Romanian Law 458/2002 updated-Quality of drinking water- Official Monitor, Bucharest 69/2011. 